\title{
Harmonics Elimination Based on Curve Fitting Method for Modular Multilevel Converters
}

\author{
Majdee Tohtayong ${ }^{1}$, Sheroz Khan ${ }^{2}$, Mashkuri Yaacob ${ }^{3}$, Siti Hajar Yusoff ${ }^{4}$, Musse Mohamud Ahmed \\ Kushsairy Kadir ${ }^{6}$, Jawad Shah ${ }^{7}$, Khairil Azhar Aznan ${ }^{8}$, and Ezzidin Aboadla ${ }^{9}$ \\ ${ }^{1}$ Department of Electrical Engineering, Princess of Naradhiwas University, Thailand \\ 1,2,3,4,8,9 Department of Electrical and Computer Engineering, International Islamic University Malaysia, Malaysia \\ ${ }^{5}$ Department of Electrical and Electronic Engineering, Universiti Malaysia Sarawak, Malaysia \\ ${ }^{6,7}$ British Malaysian Institute, Universiti Kuala Lumpur, Malaysia \\ ${ }^{1}$ majdee@gmail.com
}

\begin{abstract}
This paper presents the additional ways to figure out the switching angles for eliminating harmonic in Modular Multilevel Converters, MMCs. The switching angles equation is written in terms of nonlinear equation system, in general, one of the numerical method, named Newton-Raphson method, is used for this calculation procedure but the Newton-Raphson method takes more time for calculation that is difficult to implement the MMCs in a real-time control application. So that, numerous previous calculation methods are proposed to address this issue. To reduce the calculated time of switching angles, the Curve Fitting method is selected to assist the Newton-Raphson method and the idea of this combination method is presented in this paper. The calculation result of this combination and original Newton-Raphson method are compared and implemented in the 3-phase 7-level MMCs simulation to validate the calculation results. The Curve-Fitting can be used for calculation assisting of Newton-Raphson Method and obtains the calculation results faster than the using of lone Newton-Raphson method.
\end{abstract}

Index Terms - MMCs, Stepped Waveform, Curve Fitting, Newton-Raphson.

\section{INTRODUCTION}

Modular Multilevel Converters is a type of DC to AC power converter which is commonly used in the conversion of electrical energy from several direct current sources to a single alternative current load such as photovoltaic, fuel cell, battery, supercapacitor, etc [1]-[4]. This power converter topology can be operated in low switching frequency, mostly operating at the fundamental frequency $50 \mathrm{~Hz}$ or $60 \mathrm{~Hz}$, generating a stepped waveform with harmonics elimination and THD reduction. However, MMCs needs to be optimized switching angles to obtain the best value of THD by eliminating nearest fundamental frequency harmonic components which the amount of these switching angles depends on the number of the level of the output stepped waveform. Due to nonlinear system equation of the stepped waveform optimization produced by Fourier Transform, advanced mathematical or numerical methods are required to solve the exact value of switching angles.

Previously, there are various papers that proposed the advanced mathematical or numerical method to achieve the exact solutions of the switching angles by calculating on PC then store the values of the switching angles in microcontroller as programmed PWM such as Newton-Raphson Method [5], Genetic Algorithm [6], Homotopic Algorithm [7], Particle Swarm Optimization [8], Ant Colony Optimization [9], Resultant Theory Method [10], etc.

This paper presents the switching angles calculation by using Newton-Raphson method and combination with Curvefitting method. Section II is briefing the concept of HalfBridge Modular Multilevel Converters. The concept of switching angles calculation of combination of NewtonRaphson method and Curve-fitting method is explained in Section III and shows the calculation results in Section IV. Simulation results are validated in Section V, and conclusion in Section VI.

\section{Half-Bridge Modular MultileVel ConVERTERS}

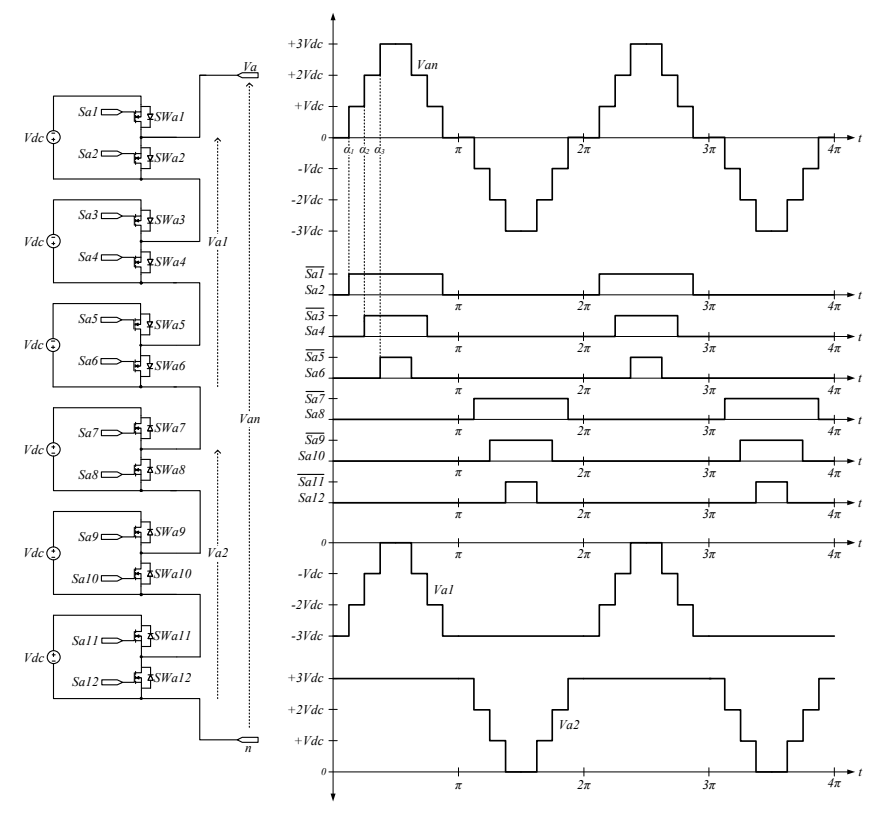

Fig. 1 Half-Bridge Modular Multilevel Converters

In the case of power converter application on $\mathrm{AC}$ output load demand by several low-voltage DC sources, 
the Half-Bridge Modular Multilevel Converters is the most common selected converter topology due to each Half-Bridge module of the topology can be connected to separate DC source and cascaded connection of the output of each module to obtain the AC voltage[11]. Besides, the output voltage can be regulated or adjusted by changing the value of modulation index, without using $\mathrm{DC}$ to $\mathrm{DC}$ converter for regulating the voltage.

Half-Bridge MMCs consists of several modules of seriesconnected Half-Bridge Converter. Each of module consists of two power switches and a DC Source. This two-switch of the module are contrary operated. However, in this topology, the ideal DC voltage of each module must give the same voltage value. The voltage outputs of several Half-Bridge modules are connected to obtain AC stepped-waveform output and it must be generated by shaping closely sinusoidal waveform that is satisfactory by lower THD value.

The different operated pulse-width output voltage of each module of Half-Bridge MMCs is combined to make a stepped waveform, whereas Van is connected to the load and the operation waveform as shown in Fig. 1, which is illustrated a single-phase Half-Bridge MMCs for generating 7-level of the output voltage. Here, this six-module of the circuit can generate 7-level voltage output depending on the voltage summary of DC sources, $+3 \mathrm{Vdc}$ at $\mathrm{Val}$ and $-3 \mathrm{Vdc}$ at $\mathrm{Van}$. The number of output level is $m=s+1$ where $s$ is the number of module and $m$ is the number of output level. The peak of the output voltage is equal to $V a n_{\text {peak }}=s V d c$.

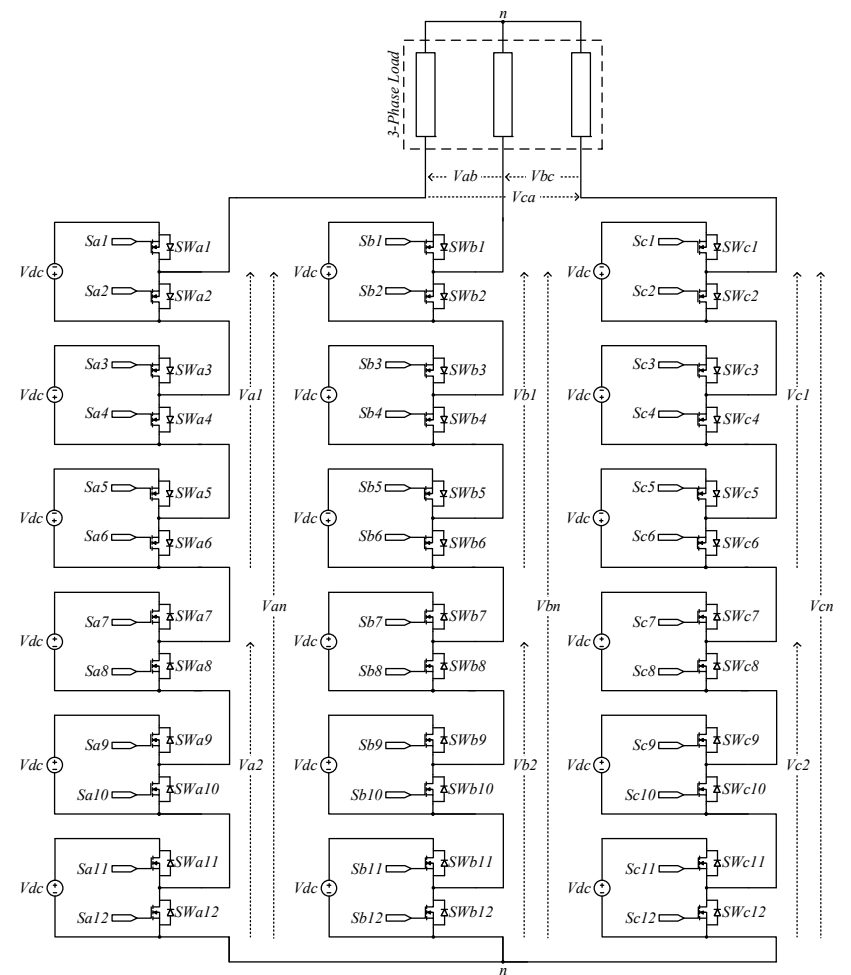

Fig. 2 Three-Phase Seven-Level Modular Multilevel Converters

As it can be seen, there are three upper side modules for releasing positive output voltage at $\mathrm{Val}$, whereas three lower side modules for releasing negative output voltage at $\mathrm{Va}$. In addition, every single module of a single-phase half-bridge MMCs generates different waveform while compared to other modules. Moreover, each group of upper and lower side modules is working at the half period of a cycle of the output voltage. For instance, SWa1, SWa2, SWa3, SWa4, SWa5, and $S W a 6$ are working on the first half period. The switches $S W a 7$, SWa8, SWa9, SWa10, SWa11, and SWa12 are working on generating the second half period. However, the complementary switch pairs for a single-phase cascaded halfbridge MMCs are SWa1-SWa2, SWa3-SWa4, SWa5-SWa6, SWa7-SWa8, SWa9-SWa10, and SWa11-Swan12.

The 3-phase Half-Bridge MMCs can be constructed by using 3 group of single-phase MMCs as shown in Fig. 2 and the operating signals of the second-phase and the third-phase can use the switching angle values of the first-phase, but must be shifted $120^{\circ}$ and $240^{\circ}$, accordingly.

\section{SWitching ANGLES CALCULATION}

To operate the satisfied stepped waveform, the switching angles calculation is necessary. The PWM scheme called SHEPWM technique, Selective Harmonics Elimination PWM [12], [13], which is applied to eliminate selected harmonics for the satisfying waveform. In the case of the stepped waveform, the waveform is assumed to be a symmetrical waveform. So that, the calculation considers the switching angles on firstquarter of the waveform then the rest quarters would use the values of the first-quarter to calculate the switching angles on their own quarters following TABLE 1.

TABLE 1. The Switching Pattern Calculation

$$
\begin{aligned}
& \text { The Quarters and Switching Angles } \\
& \hline \begin{array}{c}
\text { First quarter } \\
\alpha_{1}, \alpha_{2}, \alpha_{3}
\end{array} \\
& \text { Second quarter } \\
& \quad \alpha_{4}=\pi-\alpha_{3}, \alpha_{5}=\pi-\alpha_{2}, \alpha_{6}=\pi-\alpha_{1} \\
& \text { Third quarter } \\
& \quad \alpha_{7}=\pi+\alpha_{1}, \alpha_{8}=\pi+\alpha_{2}, \alpha_{9}=\pi+\alpha_{3} \\
& \text { Fourth quarter } \\
& \quad \alpha_{10}=2 \pi-\alpha_{3}, \alpha_{11}=2 \pi-\alpha_{2}, \alpha_{12}=2 \pi-\alpha_{1} \\
& \hline \begin{array}{l}
(\omega t)=\sum_{n=1}^{\infty}\left[\frac{4 E}{n \pi} \sum_{k=1}^{s}\left(\cos \left(n \alpha_{k}\right)\right)\right] \cdot \sin (n \omega t)
\end{array}
\end{aligned}
$$

Considering the Fourier Transform on the first-quarter of the output waveform, the system of equation for MMCs operation can be written as follows:

$$
\begin{aligned}
& \cos \left(\alpha_{1}\right)+\cos \left(\alpha_{2}\right)+\cos \left(\alpha_{3}\right)=M i \frac{3 \pi}{4} \\
& \cos \left(5 \alpha_{1}\right)+\cos \left(5 \alpha_{2}\right)+\cos \left(5 \alpha_{3}\right)=0 \\
& \cos \left(7 \alpha_{1}\right)+\cos \left(7 \alpha_{2}\right)+\cos \left(7 \alpha_{3}\right)=0
\end{aligned}
$$


The equation (2) is a term of the fundamental component, the fundamental magnitude of the output voltage is described by the right-hand side of the equation. Moreover, the value of fundamental component can be defined by equation (5). Harmonic components number $5^{\text {th }}$ and $7^{\text {th }}$ are selected to eliminate that shown in equation (3) and (4), zero on the righthand side of the equations are described. However, the 3-phase operation of MMCs converter automatically eliminates the triple harmonic order such as $3^{\text {rd }}, 9^{\text {th }}, 15^{\text {th }}, 21^{\text {st }}$, etc.

$$
M i=\frac{V_{f}}{s V d c}
$$

The THD calculation for the stepped waveform output of MMCs has used the equation (6).

$$
T H D=\frac{\sqrt{\sum_{n=2}^{\infty}\left(\frac{1}{n} \sum_{k=1}^{s} \cos \left(n \alpha_{k}\right)\right)^{2}}}{\sum_{k=1}^{s} \cos \left(\alpha_{k}\right)}
$$

\section{CALCUlation Results}

To solve the nonlinear system equations, equation (2), (3), and (4), to figure out the values of alphas $\left(\alpha_{1}, \alpha_{2}\right.$, and $\left.\alpha_{3}\right)$, Newton-Raphson method is the most widely used to figure out the solutions of switching angle in various type of waveform generation. This method requires the initial guess solution or a group of them in the case of system equations. Then, the initial guess solution is improved to obtain a better second solution and it becomes the initial guess solution for the second round.

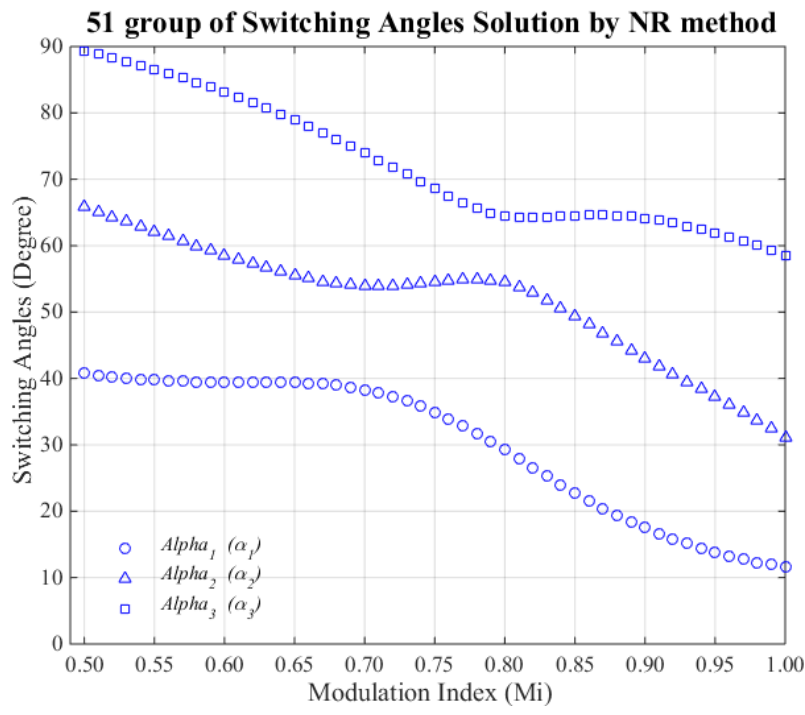

Fig. 3 The 51 group of solution releasing by Newton-Raphson Method
This procedure is repeated until the error of the current solution is satisfied which is compared to the previous solution. In terms of the wide range of the modulation index for adjusting the value of the fundamental component, this paper selects a step of 0.01 between $M i=0.5$ and $M i=1.0$ for figuring out the solutions. The 51 group of solution releasing by Newton-Raphson Method is shown in Fig. 3 and any group of the solution have 3 switching angles ( $\alpha_{1}, \alpha_{2}$, and $\left.\alpha_{3}\right)$.

As a condition of switching angles arrangement $0<\alpha_{1}<\alpha_{2}<\alpha_{3}<(\pi / 2)$, this group of solution can be used for implementing on MMCs.

The concept of Curve fitting method is constructing a curve by catching the trend of initial data across the total range of initial data that has the satisfied line of fitting to a group of data points.

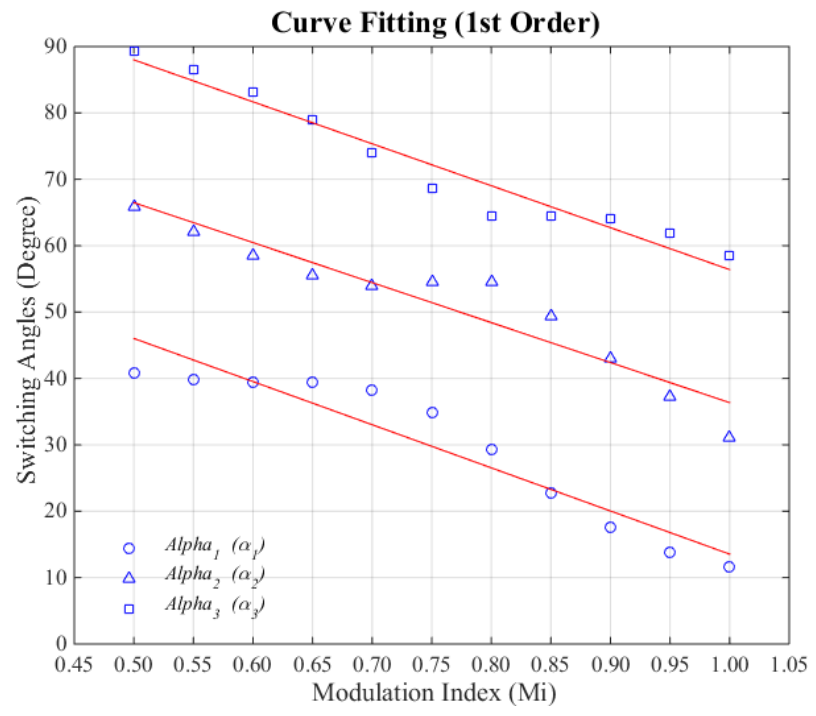

Fig. 4 The 11 group of solution releasing by Newton-Raphson Method and the 51 group of solution releasing by $1^{\text {st }}$ order Curve Fitting Method

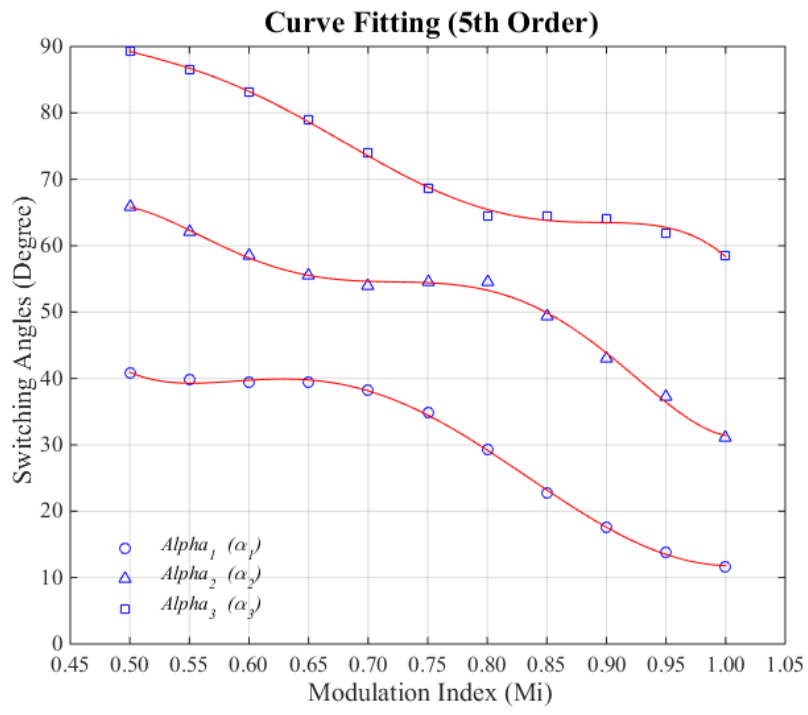

Fig. 5 The 11 group of solution releasing by Newton-Raphson Method and the 51 group of solution releasing by $5^{\text {th }}$ order Curve Fitting Method 
To implement Curve fitting method for estimating the solution of switching angles, this method needs a group of guide solutions for fitting the solution which it can be generated by using Newton-Rapson method, but the step of guide solutions can be set a bigger calculation step than using lone Newton-Rapson method. So that, 0.05 is a step of Newton-Rapson method calculation between $M i=0.5$ and $M i=1.0$ to obtain the guide solutions for Curve fitting method.

The $1^{\text {st }}, 5^{\text {th }}$, and $9^{\text {th }}$ order Curve fitting method are applied by using the group of guide solutions to estimate the solutions of switching angles. The straight-line solutions are only given by the $1^{\text {st }}$ order Curve fitting, Fig. 4 , while the $5^{\text {th }}$ order Curve fitting the lines becomes curves, Fig. 5, and the $9^{\text {th }}$ order of Curve fitting which gives the curves to tail with the solution guide, Fig. 6.

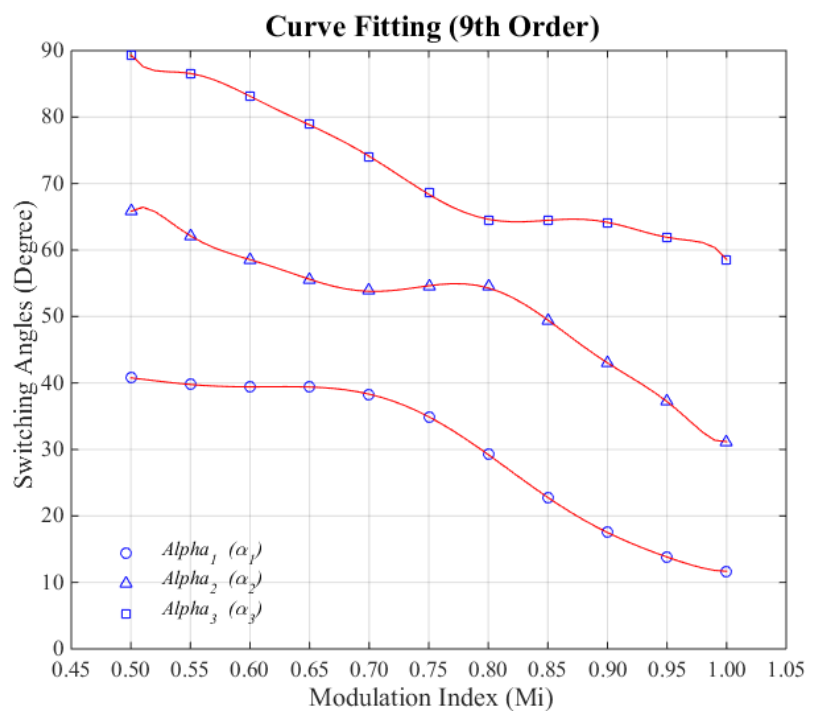

Fig. 6 The 11 group of solution releasing by Newton-Raphson Method and the 51 group of solution releasing by $9^{\text {th }}$ order Curve Fitting Method

\section{SimUlation RESUlts}

MMCs simulation using three switching angles at $M i=0.85$ from the graph in Section IV to generate a stepped waveform of Phase voltage and Line Voltage as well as their harmonic spectrums. The simulation results from the switching angles based on Newton-Rapson method are applied to MMCs simulation to display in Fig. 7 and Fig. 8, the $5^{\text {th }}$ and $7^{\text {th }}$ harmonic components are eliminated by SHEPWM technique, but $3^{\text {rd }}$ and $9^{\text {th }}$ harmonic components are eliminated by the three-phase condition.

The simulation result of $1^{\text {st }}, 5^{\text {th }}$, and $9^{\text {th }}$ order Curve fitting method is also shown the stepped waveform of Phase voltage and Line Voltage as well as their harmonic spectrums in Fig. 9, Fig. 10, Fig. 11, Fig. 12, Fig. 13, and Fig. 14 respectively. As it can be seen, all the output voltage waveform on the time domain is not clear to see their dissimilar, but the simulation results on the frequency domain, which represent the magnitude of harmonics, can be clearly seen the difference.

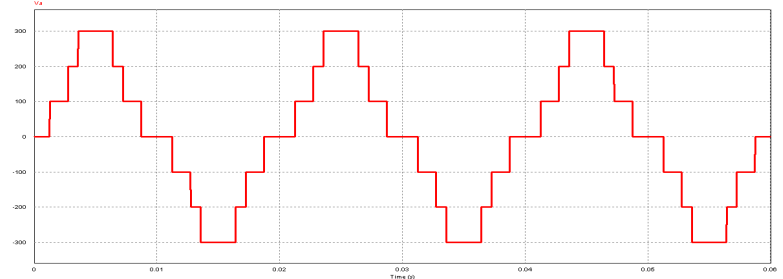

(a)

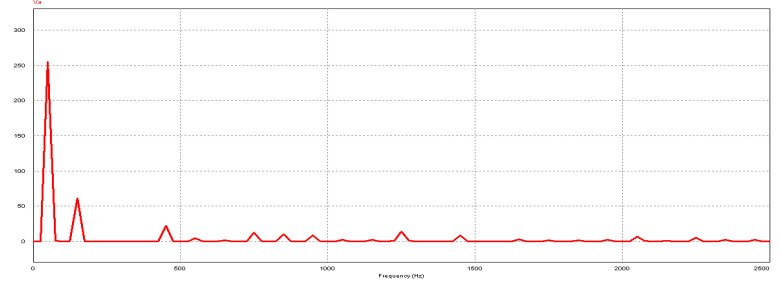

(b)

Fig. 7 (a) Phase output voltage at $M i=0.85$ and (b) its spectrums releasing the switching angles by using Newton-Raphson method

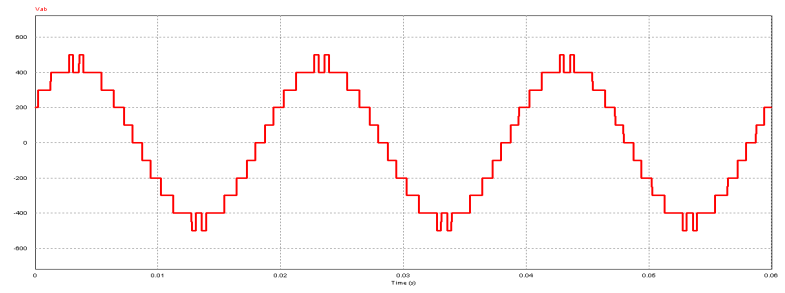

(a)

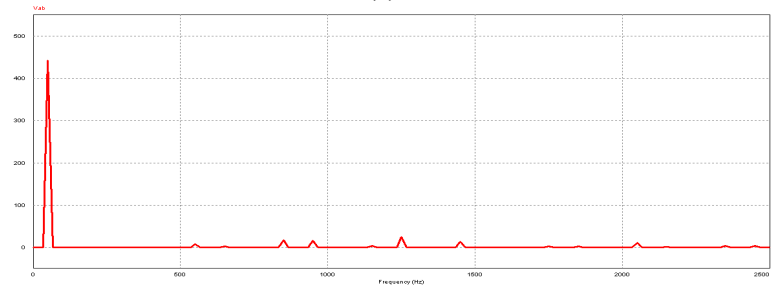

(b)

Fig. 8 (a) Line output voltage at $M i=0.85$ and (b) its spectrums releasing the switching angles by using Newton-Raphson method

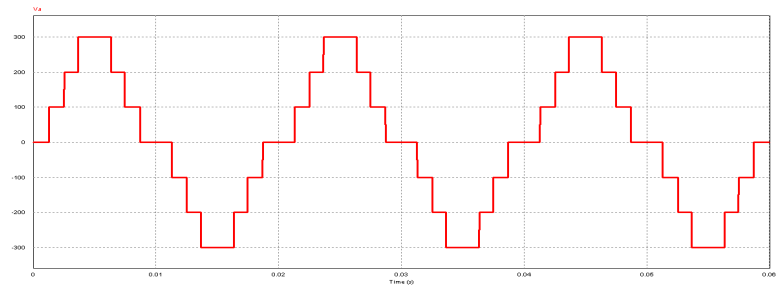

(a)

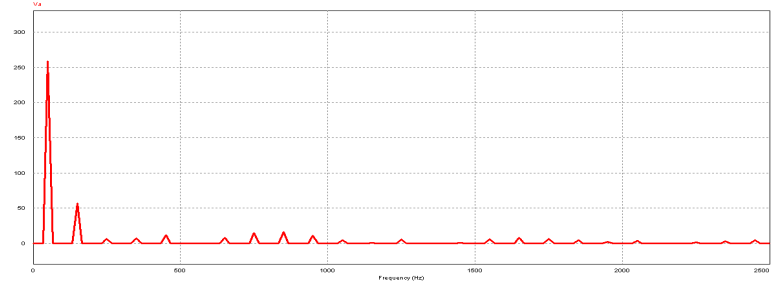

(b)

Fig. 9 (a) Phase output voltage at $M i=0.85$ and (b) its spectrums releasing the switching angles by using $1^{\text {st }}$ order Curve Fitting method 


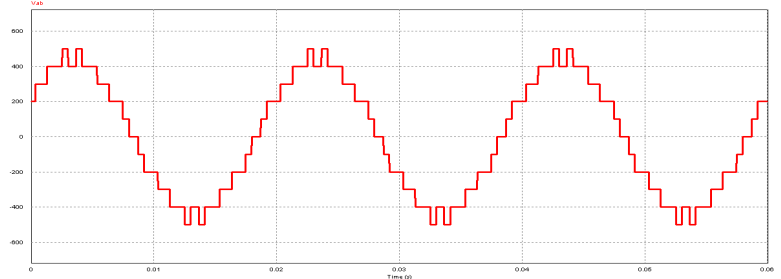

(a)

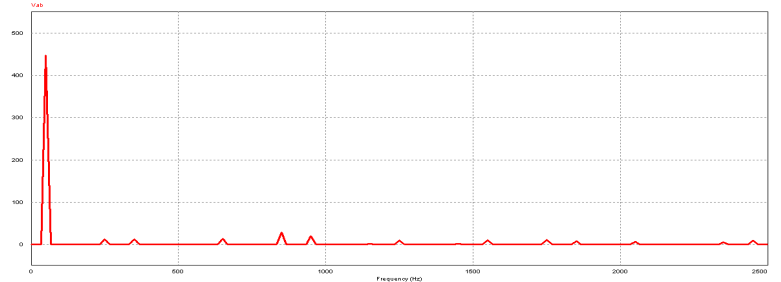

(b)

Fig. 10 (a) Line output voltage at $M i=0.85$ and (b) its spectrums releasing the switching angles by using $1^{\text {st }}$ order Curve Fitting method

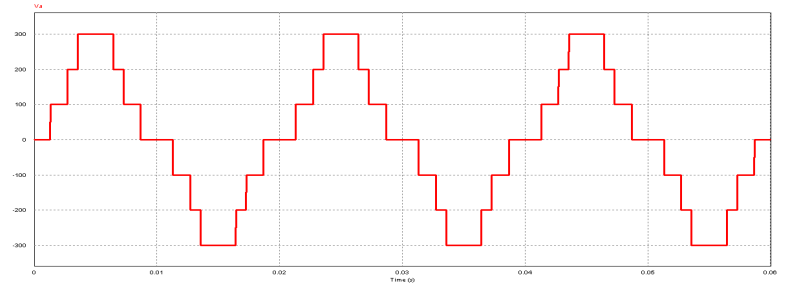

(a)

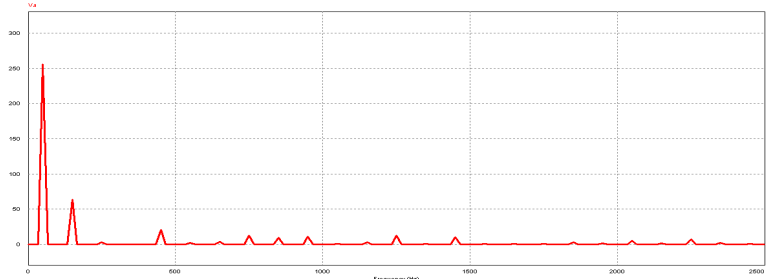

(b)

Fig. 11 (a) Phase output voltage at $M i=0.85$ and (b) its spectrums releasing the switching angles by using $5^{\text {th }}$ order Curve Fitting method

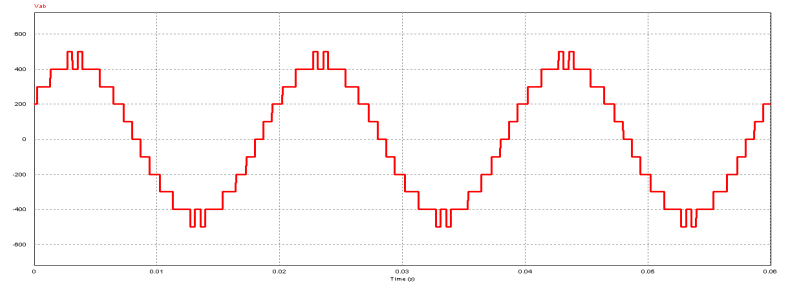

(a)

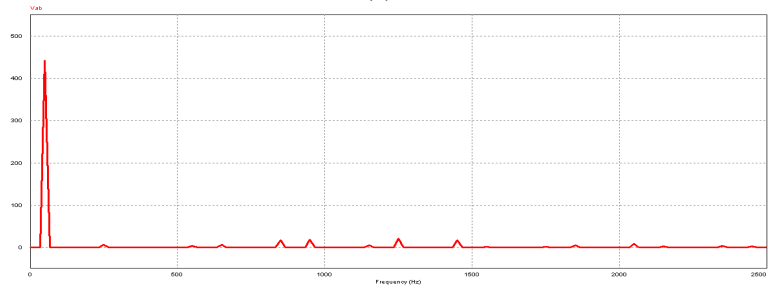

(b)

Fig. 12 (a) Line output voltage at $M i=0.85$ and (b) its spectrums releasing the switching angles by using $5^{\text {th }}$ order Curve Fitting method

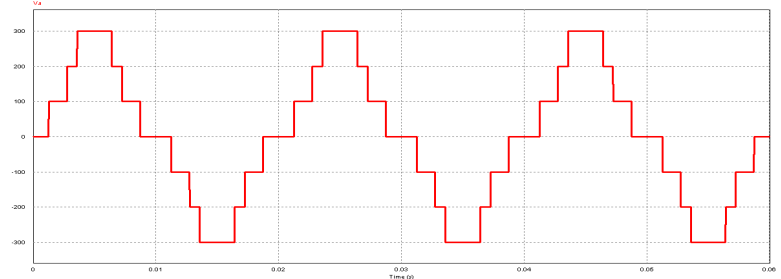

(a)

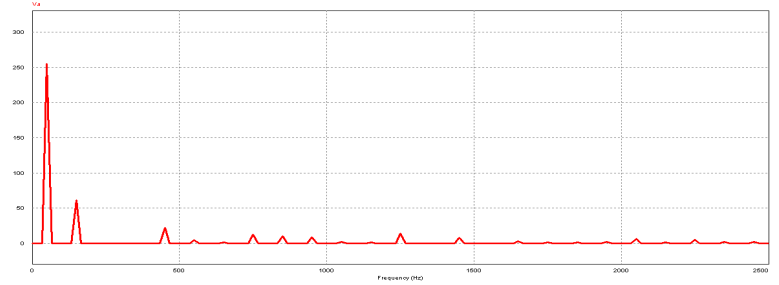

(b)

Fig. 13 (a) Phase output voltage at $M i=0.85$ and (b) its spectrums releasing the switching angles by using $9^{\text {th }}$ order Curve Fitting method

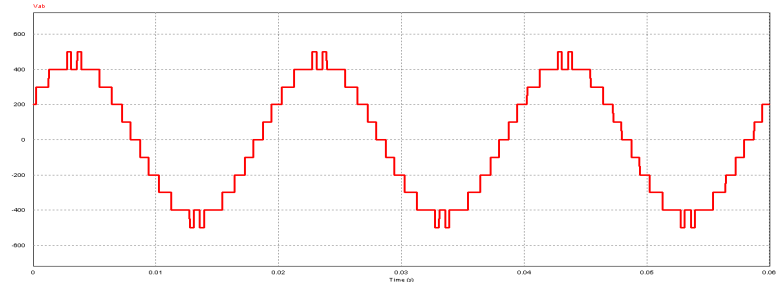

(a)

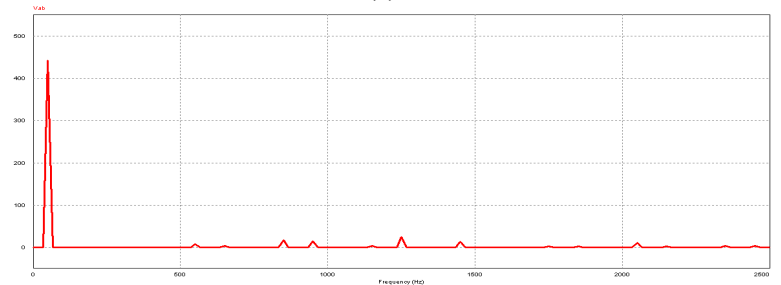

(b)

Fig. 14 (a) Line output voltage at $M i=0.85$ and (b) its spectrums releasing the switching angles by using $9^{\text {th }}$ order Curve Fitting method

The unwanted harmonics, $5^{\text {th }}$ and $7^{\text {th }}$ components, of $1^{\text {st }}$ and $5^{\text {th }}$ order Curve fitting method still appear with small amplitude on the frequency domain, but the $9^{\text {th }}$ order Curve fitting method shows that the unwanted harmonics spectrums are eliminated. As the same condition of a three-phase connection, the $3^{\text {rd }}$ and $9^{\text {th }}$ harmonic components are automatically eliminated.

\section{CONCLUSION}

This paper has proposed harmonics elimination based on curve fitting method for modular multilevel converters. The switching angles solution of Newton-Raphson method and Curve fitting method based on SHEPWM technique are illustrated to use the values of them on the MMCs simulation and compare the simulation results. Regarding simulation results, the 9th order Curve fitting method can be used for mocking the switching angle solution of Newton-Rapson method. 


\section{REFERENCES}

[1] M. Quraan, T. Yeo, and P. Tricoli, "Design and Control of Modular Multilevel Converters for Battery Electric Vehicles," IEEE Trans. Power Electron., vol. 31, no. 1, pp. 507-517, 2016.

[2] X. Liang, "Emerging Power Quality Challenges Due to Integration of Renewable Energy Sources," IEEE Trans. Ind. Appl., no. c, pp. 1-1, 2016.

[3] G. Su, "Multilevel DC Link Inverter," IEEE Trans. Ind. Appl., vol. 41, no. 3, pp. 848-854, 2005.

[4] K. B. Raj, M. Jayaraman, and V. T. Sreedevi, "Power quality analysis of a PV fed seven level cascaded H-bridge multilevel inverter," Proc. 2014 IEEE Int. Conf. Adv. Commun. Control Comput. Technol. ICACCCT 2014, no. 978, pp. 281-285, 2015.

[5] Krismadinata, A. R. Nasrudin, W. P. Hew, and J. Selvaraj, "Elimination of harmonics in photovoltaic seven-level inverter with Newton-Raphson optimization," 3rd Int. Conf. Sustain. Futur. Hum. Secur. (SUSTAIN 2012), vol. 17, pp. 519-528, 2013.

[6] K. El-Naggar and T. H. Abdelhamid, "Selective harmonic elimination of new family of multilevel inverters using genetic algorithms," Energy Convers. Manag., vol. 49, no. 1, pp. 89-95, 2008.

[7] M. G. Hosseini Aghdam, S. H. Fathi, and G. B. Gharehpetian, "Elimination of harmonics in a multi-level inverter with unequal DC sources using the homotopy algorithm," IEEE Int. Symp. Ind. Electron. 2007. ISIE 2007., pp. 578-583, 2007.
[8] M. Tarafdar Hagh, H. Taghizadeh, and K. Razi, "Harmonic minimization in multilevel inverters using modified species-based particle swarm optimization," IEEE Trans. Power Electron., vol. 24, no. 10, pp. 2259-2267, 2009.

[9] K. Sundareswaran, K. Jayant, and T. N. Shanavas, "Inverter harmonic elimination through a colony of continuously exploring ants," IEEE Trans. Ind. Electron., vol. 54, no. 5, pp. 2558-2565, 2007.

[10] J. Chiasson, L. Tolbert, K. Mckenzie, and Z. Du, "Eliminating Harmonics in a Multilevel Converter using Resultant Theory," Power Electron. Spec. Conf. 2002. PESC 02., pp. 503-508, 2002.

[11] G. P. Adam and B. W. Williams, "Half-and full-bridge modular multilevel converter models for simulations of full-scale HVDC links and multiterminal DC grids," IEEE J. Emerg. Sel. Top. Power Electron., vol. 2, no. 4, pp. 1089-1108, 2014.

[12] L. Li, D. Czarkowski, Y. Liu, and P. Pillay, "Multilevel selective harmonic elimination PWM technique in series-connected voltage inverters," IEEE Trans. Ind. Appl., vol. 36, no. 1, pp. 160-170, 2000.

[13] H. Bierk, A. Al-Judi, A. H. M. A. Rahim, and E. Nowicki, "Elimination of low-order harmonics using a modified SHE-PWM technique for medium voltage induction motor applications," 2009 IEEE Power Energy Soc. Gen. Meet. PES '09, pp. 1-9, 2009. 